\title{
Effect of Psycho-Educational Program on Depression among Drug Addict Patients at Assiut University Hospital
}

\author{
Shymaa Mohammed Sayed ${ }^{1}$, Hossam Eddin Khalifa Ahmad ${ }^{2}$, Nadia Ebraheem Sayied ${ }^{3}$, Azza Mohamed Abd \\ El-Aziz ${ }^{4}$. \\ 1. Assistant Lecturer of Psychiatric and Mental Health Nursing, Faculty of Nursing, Assiut University, Egypt. \\ 2. Professor of psychiatry, Faculty of medicine, Assiut University, Egypt. \\ 3. Assistant Professor of Psychiatric and Mental Health Nursing, Faculty of Nursing, Assiut University, Egypt. \\ 4. Lecturer of Psychiatric and Mental Health Nursing, Faculty of Nursing, Assiut University, Egypt.
}

\begin{abstract}
Psycho-educational program which enhanced health behaviors, increased coping skills, give information about what substance abuse is, and its complications on drug addict patients physical and mental health. Aim of the study: Evaluate the effect of psycho-educational program on depression among drug addict patients. Design: QuasiExperimental pretest posttest controlled design was used. Subjects and method: The studied sample consisted of 100 drug addict patients, 50 were study group \& 50 were control group. Tools: Personal data, pattern of drug addiction questionnaire, and Beck Depression Inventory (BDI). Results: pre psycho-educational program, the majority of drug addict patients had severe levels of depression while, post program, the drug addict patients (study group) had less levels of depression than control group who didn't received psycho-educational program. Conclusion: Psycho-educational program had positive effects on levels of depression among study group than control group. Recommendations: Psycho-educational program should be part of the treatment strategies among drug addict patients and their families.
\end{abstract}

\section{Key Words: Depression, Drug Addict Patients \& Psycho-educational Program.}

\section{Introduction}

Drug addiction is one of the most life threatening illnesses worldwide, which can be associated with adverse consequences related to repeated use of the substance. Untreated drug addiction might result in disturbances in social, occupational, or recreational activities. Furthermore, intoxication and withdrawal might have devastating impacts on health Ahmadi et al., ( 2016).

According to American Medical Association, (2015) reported that, $50 \%$ of individuals with severe mental disorders are affected by substance abuse. 37 $\%$ of alcohol abusers and $53 \%$ of drug abusers also have at least one serious mental illness, of all patients diagnosed as mentally ill, and $29 \%$ abuse either alcohol or drugs.

In this respect, Mather et al., (2015) reported that, estimates of the total overall costs of substance abuse in the United States; including productivity, health and crime-related costs exceed $\$ 600$ billion annually. As staggering as these numbers are, they do not fully describe the breadth of destructive public health and safety implications of drug abuse and addiction, such as family disintegration, loss of employment, failure in school, domestic violence, and child abuse.

In the same convex to Comer \& Ronald (2014) stated that, depressive symptoms may develop, as a direct result of taking drugs or as part of withdrawal symptoms when drug-taking stops. Low mood in withdrawal may be brief and self-limiting. But sometimes it can lead to serious, prolonged depressive symptoms. Heavy drug use can lead to major financial problems, difficulties with relationships or trouble with the law. A person taking recreational drugs is likely to have more of these pressures, which may trigger depression.

Drug addiction can cause depression and depression can cause drug addiction. There are a number of drugs that patients use and abuse that can directly affect the brain and cause depression. For example, marijuana slows down brain functioning and diminishes cognitive abilities and can cause depression in a significant number of individuals and alcohol can do the same thing. However, cocaine tends to elevate patient's moods, but when they come off it; they often experience a crash into depression. There is a whole long list of other frequent drugs of abuse that also can lead to depression either during the time when the individual is intoxicated with the drug or during the withdrawal phase (David, 2011). According to National Institute of Drug Abuse (2014) reported that, psycho educational program about drug addiction is an important part of helping individuals understands the many aspects of this topic. Psycho educational program are information can include factual data about what substance 
abuse is; warning signs of addiction; information about how specific drugs affect the mind and body; the consequences that addiction can have on one's physical and mental health, family, relationships, other areas of functioning; and how and why substances are abused. Psycho-educational program may also include information on how to be supportive during the detoxification and rehabilitation process.

It was reported by Maye \& Seerano (2012) that, nurses working in a drug addiction unit are often charged with monitoring the detoxification of patients who are admitted. So, nurses must assess patient for signs and symptoms of depression (e.g. feeling of sadness, helplessness, hopelessness, worthlessness, low self-esteem, change in sleep, and change in appetite). Nurses must assist patient to identify negative effects of drug dependency, they must interact with the patient in a slow paced, low and firm tone and do not hurry the patient when interacting, instead to be patient and show a sense of empathy.

\section{Significance of the study}

The problem of drug addiction has become one of the most serious problems that threaten our Egyptian society, especially after high prevalence among adolescents. The estimated prevalence of drug addiction in Egypt about more than nine million Egyptian addicts so must be intervention to reduce the aggravation of this problem (Marwan, 2018). A number of studies have indicated that $20 \%$ of patients in the Egypt with drug addiction and around $35 \%$ of patients with drug addiction have depression Mohamed et al., (2014). Individuals with drug addiction frequently suffer from depression, associated with increased morbidity and mortality along with poorer treatment outcomes and higher treatment costs. Whether it is considered as a continuous measure of depression, need for effective psycho-educational program Clark et al., (2010).

\section{Aim of the study}

This study aimed to design, implement and evaluate the effect of psycho-educational program on depression among drug patients.

\section{Research hypothesis}

Drug patients who receive psycho-educational program would have less depression level than who don't receive it.

\section{Subjects \& Method}

Research Design: Quasi- Experimental pretest posttest controlled design was used to conduct this study.

\section{Setting}

The study was carried out at inpatient of addiction management unit of Assiut University Hospital. Assiut University Hospital is the biggest hospital in Upper Egypt provides health services for Assiut city and most of the neighboring governorates. This unit contains 8 rooms; each room contains 2 beds and 1 bathroom. Nurses' number in this unit is 8 nurses gives care and medications to drug addict people as doctor order.

Sample: Non probability (purposive) sample was used, consisting of fifty (50) drug patients ( study group) received psycho-educational program and fifty (50) drug patients (control group) didn't received the psycho-educational program. Two groups of this study selected according to the following criteria Inclusion criteria: Accept to participate in the study; diagnosed with drug addiction and this age range between (15 to 50 years).

Exclusion criteria: Drug patients with mental retardation according to diagnosis of the patient that found in the patent's ticket; organic brain disorder; and history of surgical operation.

\section{Tools of the study}

Tool (1) personal data: Developed by the researcher. It included age, marital status, residence, occupation and level of education.

Tool (2) Pattern of drug addiction questionnaire This questionnaire developed by the researcher. It included: the route of administration (oral, inhalation, injection, others), age of starting abuse (years), duration of abuse (less than one year, more than one year), motivation for use (bad friends, trial, increase strength and energy, escape from life stressors, weakness of sexual ability) and desired effects (extraversion, stimulation to work, sexual potency, happiness).

Tool (3) Beck depression inventory (BDI): This scale has been developed by Beck, first published in 1961 and later revised in 1969 and copyrighted in 1979 (Polgar \& Michael, 2003) and was translated to Arabic by (Abdel- Khalek, 1998) and back translated into English to check validity and reliability and was updated by (Basher, 2010). Internal consistency showed a high value for standardized alpha (Cronbach's) $=0.92$. The questionnaire contains 21 questions about how the subject has been feeling; each question has asset of at least four possible answer choices, ranging from 0 to 3 , indicating the severity of the symptom. Items 1 to 13 assess symptoms that are psychological in nature, while items 14 to 21 assess more physical symptoms (Polgar \& Michael, 2003). The scoring system ranged from 0-63 and levels of depression are categorized as (0-13) minimal depressive symptoms, 
(14- 19) mild depression, (20- 28) moderate depression, and (29-63) severe depression.

Administrative and ethical consideration

1. An official permission was granted from the Dean of the faculty of Nursing and directed to the Head of the Neurology and Psychiatric department.

2. Research proposal approved by ethics committee in the faculty of Nursing, Assiut University.

3. There is no risk for the study subjects during application of the research.

4. The study follows common ethical principles in clinical research.

5. Informed oral consent was obtained from every patient after explaining the purpose of study.

6. Privacy and confidentiality were assured during the whole study steps.

Pilot study: A pilot study was conducted out before stating data collection. It was carried out on ten patients to check clarity, and applicability of the study tools and to estimate the time needed to collect data. These $10 \%$ patients were included in the study because on modification was done.

\section{Procedure}

\section{1) Assessment phase}

- First, screen for all drug patients attending at inpatient of addiction management unit according to determined criteria at the beginning of the study by using Beck Depression Inventory (BDI). Patients who have score on Beck Depression Inventory ranged from (14-19) identified as having depression.

- According to the previous steps, participants were grouped into two categories according to nonprobability (purposive) sample: fifty (50) study groups were received psycho-educational program and another fifty (50) control group. Based on the assessment phase, simple booklets were prepared by the researchers. The program content was revised by group of experts for content validity and relevancy based on the opinion of the experts and results of the pilot study.

\section{2) Implementation phase}

\section{First group: drug patients (study group)}

- The implementation phase included the program strategy (time and number of session, interaction methods). The number of session was three sessions per week (the session lasting about 60 to 90 minutes) for each study group, each study group ranged from 3 to 5 patients. The interaction session was conducted at inpatient of addiction management unit at Assiut university hospital.

- A developed booklet by the researcher was given to each patient. Psych- educational program is included 5 sessions:-
- Frist session: Introduce the meaning of drug addiction and causes that lead to drug addiction, signs and symptoms of drug addiction according to the type of drugs.

- Second session: Help drug addict patients to identify the health risks and complications of drug addiction which affected by the psychological, social, family aspects.

- Third session: Help drug addict patients to review and identify the health risks and complications of drug addiction that effect on organic systems of the body.

- Fourth session: Help drug addict patients to recognize the strategies that help them to change their behavior. Also, Help drug addict patients to identify the meaning of relapse and methods of prevention.

- Fifth session: Help drug addict patients to identify the meaning of depression and its relationship with drug addiction and symptoms of depression.

3) Evaluation phase: Drug patients (study group) were assessed immediately after program implementation by Beck Depression Inventory (BDI). Second group: control group

The control group consisted of (50) drug addict patients only received their treatment of drug addiction only and didn't participate in psychoeducational program but should be assessed at the same time of the study group pre-post- assessment and should be assessed too after the patient of the prods for other group depend on the traditional treatment in the unit.

\section{Statistical Analysis}

The data were computerized and verified using the SPSS (Statistical Package for Social Science) version 20 to made tabulation and statistical analysis. For quantitative data, the frequencies, percentages, paired t-test; Pearson correlation coefficient, mean and standard deviation were calculated. P- Value is considered significant if it was less than 0.05 . 
Result

Table (1): Comparison between study group and control group regarding personal data $(n=100)$.

\begin{tabular}{|c|c|c|c|c|c|}
\hline Variables & \multicolumn{2}{|c|}{$\begin{array}{c}\text { Study }(\mathrm{n}=50) \\
\text { group }\end{array}$} & \multicolumn{2}{|c|}{$\begin{array}{c}\text { Control }(n=50) \\
\text { group }\end{array}$} & \multirow[t]{2}{*}{ P. value } \\
\hline \multicolumn{5}{|l|}{ Age } & \\
\hline Range & \multicolumn{2}{|c|}{$(18-50)$} & \multicolumn{2}{|c|}{$(18-50)$} & \\
\hline Mean \pm SD & \multicolumn{2}{|c|}{$29.06 \pm 7.55$} & \multicolumn{2}{|c|}{$29.48 \pm 6.80$} & \\
\hline Variables & No. & $\%$ & No. & $\%$ & \\
\hline \multicolumn{6}{|l|}{ Age group } \\
\hline \multirow{4}{*}{$\begin{array}{l}16->20 \text { years } \\
20->30 \text { years } \\
30->40 \text { years } \\
40->50 \text { years }\end{array}$} & 3 & 6.00 & 3 & 6.00 & \multirow{4}{*}{.333} \\
\hline & 32 & 64.00 & 26 & 52.00 & \\
\hline & 10 & 20.00 & 18 & 36.00 & \\
\hline & 5 & 10.00 & 3 & 6.00 & \\
\hline \multicolumn{6}{|l|}{ Marital status } \\
\hline \multirow{2}{*}{$\begin{array}{l}\text { Single } \\
\text { Married }\end{array}$} & 30 & 60.00 & 27 & 54.00 & \multirow{2}{*}{.545} \\
\hline & 20 & 40.00 & 23 & 46.00 & \\
\hline \multicolumn{6}{|l|}{ Residence } \\
\hline \multirow{2}{*}{$\begin{array}{l}\text { Rural } \\
\text { Urban }\end{array}$} & 33 & 66.00 & 35 & 70.00 & \multirow{2}{*}{.668} \\
\hline & 17 & 34.00 & 15 & 30.00 & \\
\hline \multicolumn{6}{|l|}{ Occupation } \\
\hline \multirow{5}{*}{$\begin{array}{l}\text { Not work } \\
\text { Employee } \\
\text { Farmer } \\
\text { Student } \\
\text { Manual workers }\end{array}$} & 2 & 4.00 & 1 & 2.00 & \multirow{5}{*}{.890} \\
\hline & 8 & 16.00 & 7 & 14.00 & \\
\hline & 5 & 10.00 & 3 & 6.00 & \\
\hline & 2 & 4.00 & 2 & 4.00 & \\
\hline & 33 & 66.00 & 37 & 74.00 & \\
\hline \multicolumn{6}{|c|}{ Educational level } \\
\hline \multirow{4}{*}{$\begin{array}{l}\text { Primary } \\
\text { Preparatory } \\
\text { Secondary } \\
\text { University }\end{array}$} & 5 & 10.00 & 2 & 4.00 & \multirow{4}{*}{.609} \\
\hline & 10 & 20.00 & 9 & 10.00 & \\
\hline & 29 & 58.00 & 34 & 68.00 & \\
\hline & 6 & 12.00 & 5 & 18.00 & \\
\hline
\end{tabular}

* Statistically significant difference $(p<0.05)$

** statistically significant difference $(p<0.01)$

Table (2): Comparison between study group and control group regarding pattern of drug addiction data $(\mathbf{n}=100)$.

\begin{tabular}{|c|c|c|c|c|c|}
\hline \multirow[t]{2}{*}{ Variables } & \multicolumn{2}{|c|}{$\begin{array}{c}\text { Study }(n=50) \\
\text { group }\end{array}$} & \multicolumn{2}{|c|}{$\begin{array}{c}\text { Control }(n=50) \\
\text { group }\end{array}$} & \multirow[t]{2}{*}{ P. value } \\
\hline & No. & $\%$ & No. & $\%$ & \\
\hline \multicolumn{6}{|l|}{ Diagnosis } \\
\hline Poly-drug addict & 30 & 60.00 & 26 & 52.00 & \multirow{2}{*}{.420} \\
\hline Single-drug addict & 20 & 40.00 & 24 & 48.00 & \\
\hline \multicolumn{6}{|l|}{ Types of drug use } \\
\hline Tamol or tramadol & 8 & 16.00 & 12 & 24.00 & \multirow{5}{*}{.694} \\
\hline Hashish & 4 & 8.00 & 3 & 6.00 & \\
\hline Opium & 5 & 10.00 & 7 & 14.00 & \\
\hline Cocain & 3 & 6.00 & 2 & 4.00 & \\
\hline Mixed(Tamol , tramadol, Hashish or Opium) & 30 & 60.00 & 26 & 52.00 & \\
\hline \multicolumn{6}{|l|}{ Methods of drug use } \\
\hline Oral & 38 & 76.00 & 38 & 76.00 & \multirow{3}{*}{.904} \\
\hline Inhalation & 4 & 8.00 & 3 & 6.00 & \\
\hline Injection & 8 & 16.00 & 9 & 18.00 & \\
\hline
\end{tabular}




\begin{tabular}{|c|c|c|c|c|c|}
\hline \multirow{2}{*}{ Variables } & \multicolumn{2}{|c|}{$\begin{array}{c}\text { Study }(n=50) \\
\text { group }\end{array}$} & \multicolumn{2}{|c|}{$\begin{array}{c}\text { Control }(n=50) \\
\text { group }\end{array}$} & \multirow[t]{2}{*}{ P. value } \\
\hline & No. & $\%$ & No. & $\%$ & \\
\hline $\begin{array}{l}\text { Age of starting abuse( in years) } \\
\text { Range } \\
\text { Mean } \pm \text { SD }\end{array}$ & \multicolumn{2}{|c|}{$\begin{array}{c}15: 40 \\
\mathbf{2 2 . 8 8} \pm \mathbf{5 . 8 9}\end{array}$} & \multicolumn{2}{|c|}{$\begin{array}{c}16: 34 \\
\mathbf{2 2 . 9 6} \pm 4.44\end{array}$} & \\
\hline \multicolumn{6}{|l|}{ Duration of abuse } \\
\hline \multirow{2}{*}{$\begin{array}{l}\text { Less than one year } \\
\text { More than one year }\end{array}$} & 1 & 2.00 & 5 & 10.00 & \multirow{2}{*}{.092} \\
\hline & 49 & 98.00 & 45 & 90.00 & \\
\hline \multicolumn{6}{|l|}{ Motivation for use } \\
\hline Bad friends & 20 & 40.00 & 16 & 32.00 & \multirow{5}{*}{.576} \\
\hline Trial & 6 & 12.00 & 11 & 22.00 & \\
\hline Increase strength and energy & 16 & 32.00 & 13 & 26.00 & \\
\hline Escape from life stressors & 2 & 4.00 & 4 & 8.00 & \\
\hline weakness of sexual ability & 6 & 12.00 & 6 & 12.00 & \\
\hline \multicolumn{6}{|l|}{ Desired effects } \\
\hline extraversion & 15 & 30.00 & 20 & 40.00 & \multirow{4}{*}{.713} \\
\hline Stimulation to work & 27 & 54.00 & 23 & 46.00 & \\
\hline The feeling of sexual potency & 6 & 12.00 & 6 & 12.00 & \\
\hline Happiness & 2 & 4.00 & 1 & 2.00 & \\
\hline
\end{tabular}

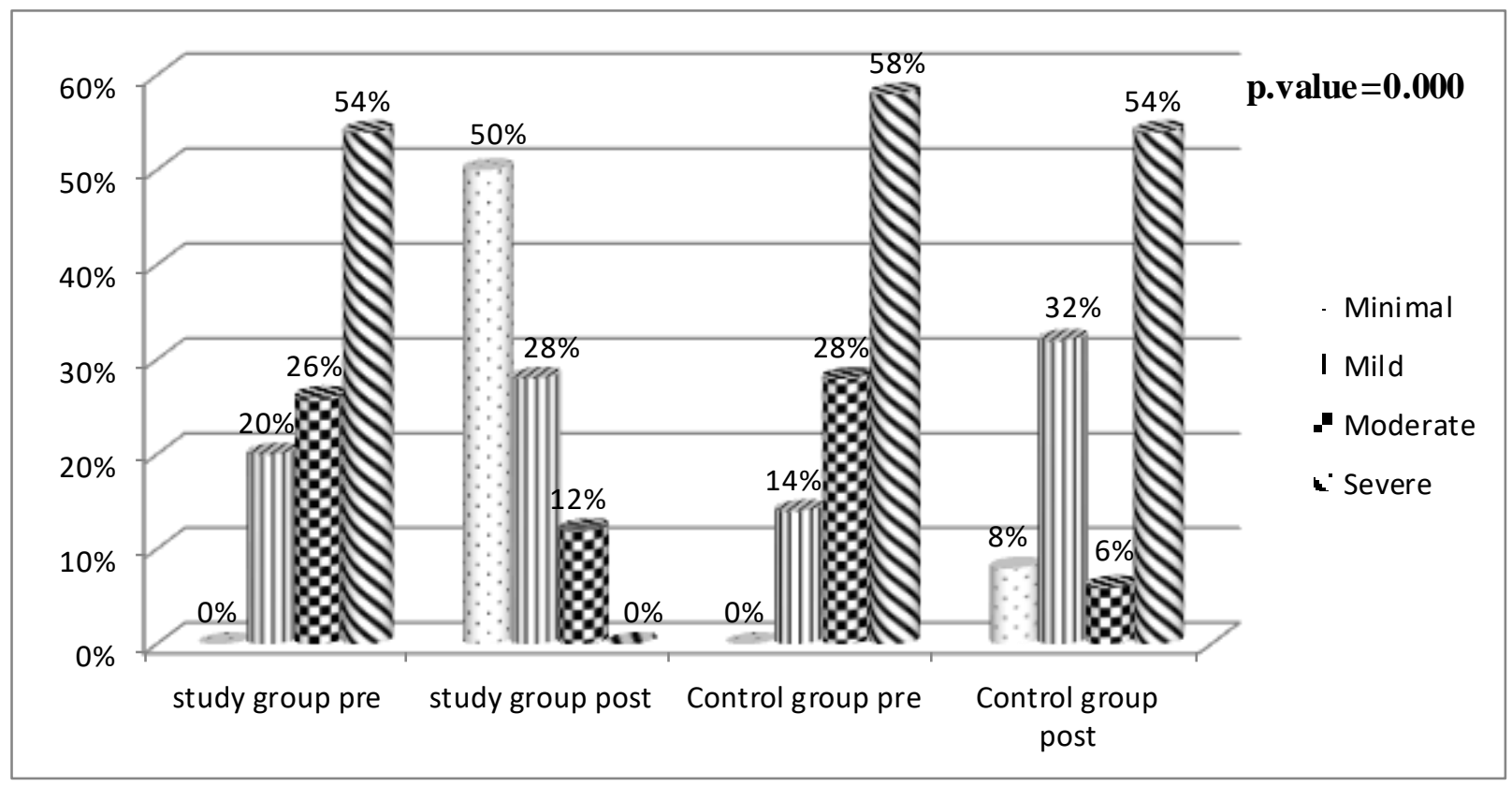

Figure (1): Comparison between pre and post psycho-educational program of drug addict patients for study and control group regarding depression levels according to Beck Depression Inventory. 
Table (3): Relationship between pre and post psycho-educational program for mean score of depression and personal data among study and control group $(n=100)$.

\begin{tabular}{|c|c|c|c|c|c|c|}
\hline \multirow{3}{*}{ Variables } & \multicolumn{3}{|c|}{ Study $(n=50)$ group } & \multicolumn{3}{|c|}{ Control $(n=50)$ group } \\
\hline & \multicolumn{2}{|c|}{ Mean \pm SD of depression } & \multirow{2}{*}{$\begin{array}{c}\text { P. } \\
\text { value }\end{array}$} & \multicolumn{2}{|c|}{ Mean \pm SD of depression } & \multirow{2}{*}{ P. value } \\
\hline & pre & post & & pre & post & \\
\hline \multicolumn{7}{|l|}{ Age groups } \\
\hline $16->20$ years & $31.30 \pm 1.64$ & $11.50 \pm 3.76$ & \multirow{4}{*}{.000} & $22.33 \pm 8.55$ & $23.86 \pm 9.23$ & \multirow{4}{*}{.609} \\
\hline $20->30$ years & $25.40 \pm 6.40$ & $13.64 \pm 6.59$ & & $25.71 \pm 6.71$ & $24.30 \pm 6.17$ & \\
\hline $30->40$ years & $27.25 \pm 7.32$ & $16.59 \pm 7.61$ & & $29.15 \pm 4.87$ & $27.84 \pm 6.18$ & \\
\hline $40->50$ years & $27.60 \pm 5.22$ & $14.69 \pm 7.86$ & & $26.16 \pm 5.25$ & $24.03 \pm 3.06$ & \\
\hline \multicolumn{7}{|l|}{ Marital status } \\
\hline Single & $26.88 \pm 6.37$ & $14.30 \pm 6.73$ & \multirow{2}{*}{.000} & $25.00 \pm 6.58$ & $24.00 \pm 6.04$ & \multirow{2}{*}{.056} \\
\hline Married & $25.54 \pm 6.43$ & $14.13 \pm 6.52$ & & $28.57 \pm 5.30$ & $27.61 \pm 6.45$ & \\
\hline \multicolumn{7}{|l|}{ Residence } \\
\hline Rural & $25.79 \pm 6.66$ & $14.60 \pm 6.63$ & \multirow{2}{*}{.000} & $26.72 \pm 6.24$ & $24.10 \pm 6.96$ & \multirow{2}{*}{.291} \\
\hline Urban & $27.41 \pm 6.55$ & $13.52 \pm 7.77$ & & $26.46 \pm 6.44$ & $23.31 \pm 6.83$ & \\
\hline \multicolumn{7}{|l|}{ Occupation } \\
\hline Not work & $32.35 \pm 2.75$ & $19.20 \pm 0.00$ & \multirow{5}{*}{.001} & $32.30 \pm 0.00$ & $29.10 \pm 0.00$ & \multirow{5}{*}{.099} \\
\hline Employee & $29.77 \pm 4.71$ & $12.95 \pm 7.66$ & & $28.52 \pm 5.22$ & $23.20 \pm 6.80$ & \\
\hline Farmer & $21.72 \pm 5.74$ & $19.40 \pm 9.09$ & & $27.66 \pm 5.63$ & $25.83 \pm 2.91$ & \\
\hline Student & $31.25 \pm 2.75$ & $21.20 \pm 9.89$ & & $24.90 \pm 9.19$ & $24.10 \pm 7.07$ & \\
\hline Manual workers & $25.55 \pm 6.47$ & $13.64 \pm 6.23$ & & $26.15 \pm 6.49$ & $24.54 \pm 6.32$ & \\
\hline \multicolumn{7}{|c|}{ Level of education } \\
\hline Primary & $19.46 \pm 6.63$ & $14.80 \pm 4.92$ & \multirow{4}{*}{.008} & $22.40 \pm 0.00$ & $21.20 \pm 9.89$ & \multirow{4}{*}{.893} \\
\hline Preparatory & $27.31 \pm 6.37$ & $14.15 \pm 6.06$ & & $25.80 \pm 7.11$ & $23.46 \pm 6.00$ & \\
\hline Secondary & $26.43 \pm 6.01$ & $13.00 \pm 6.76$ & & $27.16 \pm 6.14$ & $24.31 \pm 5.95$ & \\
\hline University & $30.05 \pm 4.54$ & $19.86 \pm 9.43$ & & $26.78 \pm 6.78$ & $25.78 \pm 7.59$ & \\
\hline
\end{tabular}

Table (4): Relationship between pre and post psycho-educational program for mean score of depression and pattern of drug addiction data among study and control group $(n=100)$ :

\begin{tabular}{|c|c|c|c|c|c|c|}
\hline \multirow{3}{*}{ Variables } & \multirow{2}{*}{\multicolumn{2}{|c|}{$\begin{array}{c}\text { Study }(n=50) \text { group } \\
\text { Mean } \pm \text { SD of depression }\end{array}$}} & \multirow{3}{*}{$\begin{array}{c}P . \\
\text { value }\end{array}$} & \multirow{2}{*}{\multicolumn{2}{|c|}{$\begin{array}{c}\text { Control }(n=50) \text { group } \\
\text { Mean } \pm \text { SD of depression }\end{array}$}} & \multirow{3}{*}{$\begin{array}{c}P . \\
\text { value }\end{array}$} \\
\hline & & & & & & \\
\hline & pre & post & & pre & post & \\
\hline \multicolumn{7}{|l|}{ Diagnosis } \\
\hline Poly- drug addict & $25.95 \pm 6.86$ & $14.84 \pm 7.00$ & \multirow{2}{*}{.000} & $26.98 \pm 6.33$ & $24.12 \pm 6.62$ & \multirow{2}{*}{.733} \\
\hline Single- drug addict & $26.92 \pm 5.64$ & $13.32 \pm 7.02$ & & $26.28 \pm 6.24$ & $25.75 \pm 5.14$ & \\
\hline \multicolumn{7}{|l|}{ Types of drug use } \\
\hline Tamol or tramadol & $25.75 \pm 7.24$ & $10.61 \pm 7.99$ & \multirow{5}{*}{.004} & $26.68 \pm 6.03$ & $25.36 \pm 5.21$ & \multirow{5}{*}{.847} \\
\hline Hashish & $28.10 \pm 5.15$ & $13.17 \pm 4.21$ & & $28.60 \pm 6.40$ & $25.76 \pm 5.77$ & \\
\hline Opium & $26.36 \pm 6.12$ & $11.98 \pm 3.92$ & & $25.60 \pm 6.10$ & $24.57 \pm 4.74$ & \\
\hline Cocain & $30.20 \pm 0.00$ & $16.80 \pm 6.55$ & & $22.85 \pm 12.09$ & $20.70 \pm 9.19$ & \\
\hline $\begin{array}{l}\text { Mixed(Tamol, tramadol, Hashish } \\
\text { or Opium) }\end{array}$ & $54.09 \pm 11.33$ & $43.28 \pm 14.09$ & & $54.20 \pm 6.78$ & $48.49 \pm 12.05$ & \\
\hline \multicolumn{7}{|l|}{ Methods of drug use } \\
\hline Oral & $25.85 \pm 6.75$ & $10.33 \pm 7.31$ & \multirow{3}{*}{.000} & $27.17 \pm 6.10$ & $24.38 \pm 6.48$ & \multirow{3}{*}{.022} \\
\hline Inhalation & $28.10 \pm 5.15$ & $12.17 \pm 4.21$ & & $28.60 \pm 6.40$ & $25.76 \pm 5.77$ & \\
\hline Injection & $27.80 \pm 5.03$ & $13.03 \pm 4.81$ & & $23.76 \pm 6.59$ & $22.81 \pm 5.43$ & \\
\hline \multicolumn{7}{|l|}{ Duration of abuse } \\
\hline Less than one year & $15.20 \pm 0.00$ & $7.20 \pm 0.00$ & \multirow{2}{*}{.000} & $25.74 \pm 8.70$ & $23.54 \pm 6.10$ & \multirow{2}{*}{.043} \\
\hline More than one year & $26.57 \pm 6.22$ & $14.37 \pm 6.98$ & & $26.74 \pm 6.02$ & $24.01 \pm 6.23$ & \\
\hline \multicolumn{7}{|l|}{ Motivation for use } \\
\hline Bad friends & $27.86 \pm 5.49$ & $15.16 \pm 6.38$ & \multirow{2}{*}{.005} & $28.53 \pm 4.64$ & $26.46 \pm 4.41$ & \multirow{2}{*}{.312} \\
\hline Trial & $28.00 \pm 6.49$ & $13.51 \pm 6.00$ & & $26.68 \pm 6.52$ & $24.90 \pm 6.31$ & \\
\hline
\end{tabular}




\begin{tabular}{|c|c|c|c|c|c|c|}
\hline \multirow{3}{*}{ Variables } & \multirow{2}{*}{\multicolumn{2}{|c|}{$\begin{array}{c}\text { Study }(n=50) \text { group } \\
\text { Mean } \pm \text { SD of depression }\end{array}$}} & \multirow{6}{*}{$\begin{array}{c}\text { P. } \\
\text { value }\end{array}$} & \multirow{2}{*}{\multicolumn{2}{|c|}{$\begin{array}{c}\text { Control }(n=50) \text { group } \\
\text { Mean } \pm \text { SD of depression }\end{array}$}} & \multirow{6}{*}{$\begin{array}{c}P . \\
\text { value }\end{array}$} \\
\hline & & & & & & \\
\hline & pre & post & & pre & post & \\
\hline Increase strength and energy & $26.75 \pm 6.87$ & $11.61 \pm 7.09$ & & $24.95 \pm 6.74$ & $22.64 \pm 6.73$ & \\
\hline Escape from life stressors & $23.40 \pm 7.07$ & $17.70 \pm 9.89$ & & $25.37 \pm 4.77$ & $23.65 \pm 1.89$ & \\
\hline Weakness of sexual ability & $24.85 \pm 7.87$ & $14.35 \pm 8.58$ & & $32.00 \pm 0.46$ & $30.16 \pm 4.66$ & \\
\hline \multicolumn{6}{|l|}{ Desired effects } & \multirow{5}{*}{.425} \\
\hline extraversion & $28.06 \pm 5.55$ & $12.43 \pm 6.51$ & \multirow{4}{*}{.017} & $26.45 \pm 6.11$ & $24.85 \pm 6.46$ & \\
\hline Stimulation to work & $27.53 \pm 6.66$ & $11.17 \pm 6.16$ & & $25.65 \pm 6.64$ & $24.13 \pm 6.24$ & \\
\hline The feeling of sexual potency & $24.85 \pm 7.87$ & $14.35 \pm 2.63$ & & $32.00 \pm 4.66$ & $30.16 \pm 1.46$ & \\
\hline Happiness & $28.85 \pm 1.63$ & $13.20 \pm 1.05$ & & $21.40 \pm 3.23$ & $19.20 \pm 1.12$ & \\
\hline
\end{tabular}

Table (1): Illustrated personal data of the study and the control groups. The mean age of the study group was $(29.10 \pm 7.66)$, while that of the control group was (30.26 \pm 6.27$)$. About (64\%) of the study group and (52\%) of the control group were at age group from 21 to 30 years old; $(60 \%)$ of the study group and $(54 \%)$ of the control group were single; $(66 \%)$ of the study group and $(70 \%)$ of the control group were from rural area; $(66 \%)$ of the study group and (74\%) of the control group were manual workers; (58\%) of the study group and (68\%) of the control group have graduated from secondary school. There were no significant differences between study and control groups regarding personal data.

Table (2): Showed comparison between study and control groups regarding pattern of drug addiction which indicated that $(60 \%)$ of the study group and $(52 \%)$ of the control group were poly drug addict; $(60 \%)$ of the study group and $(52 \%)$ of the control group used mixed types as (Tamol, tramadol, Hashish or Opium). Regarding methods of drug use, $(76 \%)$ of the study and control groups used drug orally. The mean age of starting abuse of the study group was (22.88 \pm 5.89 ), while of for the control group was $(22.96 \pm 4.44)$. As regard duration of abuse, $(98 \%)$ of the study group and (90\%) of the control group used drugs for more than one year. As regard motivation for use, (40\%) of the study group and (32\%) of the control group were motivated for using drugs by bad friends. Desired effects for drug addict, more than half $(54 \%)$ of the study group and less than half $(46 \%)$ of the control group were stimulated to work. There were no significant differences between the study and control groups regarding patterns of drug addiction.

Figure (1): Showed a comparison between pre and post psycho-educational program of drug addict patients for study and control groups regarding depression levels. This figure illustrated that (54\%) of the study group and $(58 \%)$ of the control group had severe level of depression in pre psycho- educational program. As regard post psychoeducational program, $(50 \%)$ of the study group had minimal level of depression while, (54\%) of the control group still had severe level of depression. There were statistically significant differences between pre and post psycho-educational program intervention of study and control groups as regard levels of depression $(\mathrm{p}=0.000 * *)$.

Table (3): Showed that, there were statistically significant differences between pre and post psycho-educational program for mean scores of depression and personal data among study group but there were no statistically significant differences between the same relations among the control group.

Table (4): Showed that, there were statistically significant differences between pre and post psycho-educational program intervention for mean scores of depression and patterns of drug addiction among study group but there were no statistically significant differences between the same relations among the control group except in methods of drug use $(\mathrm{p}=.022)$ and duration of abuse $(\mathrm{p}=.043)$.

\section{Discussion}

Psycho-educational is an aspect of therapy that offers information, awareness and support for patients in treatment for drug and alcohol addiction. It is also an effective therapy for patients who struggle with mental health conditions such as depression (Thilo, 2014).

The current study indicated that, about more than half of the study and control groups were poly drug addict. This might be related to that; they preferred to take more than one type of drug, for being more euphoric that as reported by the patients. This result was consistent with finding of Bornovalova, et al., (2012) who found that, more than half of the study and control groups were poly drug addict. While Meray et al., (2016) found that, the majority of the study and control groups were single drug addict. 
As regard types of drug use, the current study showed that, about two thirds of the study group used mixed types and more than half of the control group used mixed types as (Tamol, tramadol, Hashish, or Opium). This finding might be due to that addicts prefer uses of mixed types of drugs as this leads to better effect and gaining more euphoria. This finding was congruent with the study of Ansari, et al., (2016) who found that, more than half of the study and control groups used mixed types as (Tamol, tramadol, Hashish, or Opium). On other hand, Johnson \& Zlotnick (2008) found that, about more than two thirds of the study and control groups used one type of drug addiction.

Regarding methods of drug use, the current study showed that, more than two thirds of the study and control groups used drug orally. This finding could be explained by oral method is easily used, has low risk and is available method to drug addict patients, as reported by the patients. In the same context, Mohamed et al., (2015) found that, more than two thirds of the study and control groups used drug orally. In contrast with Jabeen, et al., (2017) who found that, more than one quarter of the study and control groups used drug injectable.

As regard age of starting abuse, the current study revealed that, the mean age of starting abuse of the study group was between 15 to 40 years, and was between 16 to36 years the control group. This could be explained by that the main reason for intake of such drugs might be due to the nature of adolescent period of life which characterized by sense of emptiness, curiosity, discovery and the method to prove their existence and personality, as well as a method to coping with life stressors (Giardiello, 2018). This finding was similar with Austic (2015) who demonstrated that, the majority of the study and control groups initially used drugs in early age of life. In contrast with Anagnostou, et al., (2018) who found that, the majority of the study and control groups initially used drugs in the middle age of life.

As regard duration of abuse, the present study revealed that, the majority of the study and control groups used drug more than one year. This might be attributed to the drug addicts believe that drug addiction becomes a part of their daily life habit for them and being unable to stop drugs, as reported by the patients. This result was consistent with the finding of Womack et al., (2016) who found that, the majority of the study and control groups used drug more than one year. However, this finding was not supported by McHugh et al., (2017) who found that, more than two thirds of the study and control groups used drugs less than one year.

According to the motivation for drug use, the current study revealed that, more than one third of the study and control groups reported that they used drugs because companionship of bad friends motivated them to drugs use. This might be explained by that, drug addict patients used the drugs because they share with bad peers and their effect on drug use as reported by the patients. This finding was similar with El sawy et al., (2010) who found that, more than one third of the study and control groups reported that they used drugs because of bad friends. Whereas, this finding was contrary with Calsyn et al., (2010) who found that, more than two thirds of the study and control groups reported that, they used drugs because of weakness of sexual ability.

As regard desired effects of drugs, the present study revealed that, more than one third of the study and control groups reported that they used drugs because of stimulation to work. This might be explained by drug addict patients believed that drug addiction give them strength and energy that stimulate them to work as reported by the patients. This finding was congruent with Volkow (2014) who found that, more than one third of the study and control groups reported that they used drugs because of stimulation to work. While, Calsyn et al., (2010) found that, more than two thirds of the study and control groups reported that they used drugs because of feeling of sexual potency.

The present study showed that, more than half of the study and control groups had severe level of depression in pre psycho-educational program. As regard post psycho-educational program, about half of the study group had minimal level of depression, while, slightly more than half of the control group still had severe level of depression. This could be due to that, depression seems to be one of the most common symptoms which experienced by the patients when they are recovering from drug addiction Bartha et al., (2014).

This finding was congruent with Arseneault et al., (2016) who reported that, more than half of the study and control groups had severe level of depression in pre psycho-educational program. As regard post- psycho-educational program, Fortier et al., (2017) showed that about half of the study group had minimal depression while, slightly more than half of control group had severe level of depression. This result was contradicted with Rohde et al., (2018) who showed that, more than one third of the study and control groups had severe level of 
depression in pre psycho-educational program. As regard post psycho-educational program, Conner et al., (2009) found that, more than one third of the study group had minimal level of depression while, less than one quarter of the control group had severe level of depression.

The current study revealed that, there were statistically significant differences between pre and post psycho-educational program for mean scores of depression and personal data among study group while there were no statistically significant differences between pre and post psycho-educational program for mean score of depression and personal data among control group.

This finding was similar with Martinez-Vispo et al., (2018) who revealed that, there were statistically significant differences between pre and post psychoeducational program for mean scores of depression and personal data among study group but there were no statistically significant differences between pre and post psycho-educational program for mean scores of depression and personal data among control group. In contrast with Hunter et al., (2012) who found that, there were no statistically significant differences between pre and post psycho-educational program for mean scores of depression and personal data among study and control groups.

The current study showed that, there were statistically significant differences between pre and post psycho-educational program for mean scores of depression and pattern of drug addiction among study group but there were no statistically significant differences between pre and post psycho-educational program for mean scores of depression and pattern of drug addiction among control group except methods of drug use and duration of abuse.

This finding was consistent with Martinez-Vispo et al., (2018) who revealed that, there were statistically significant differences between pre and post psychoeducational program for mean scores of depression and pattern of drug addiction among study group but there were no statistically significant differences between pre and post psycho-educational program for mean scores of depression and pattern of drug addiction among control group except methods of drug use and duration of abuse. In contrast with Sancho et al; (2018) who found that, there were no statistically significant differences between pre and post psycho-educational program for mean scores of depression and pattern of drug addiction data among study and control groups.

\section{Conclusion}

Based on the results of present study, it can be concluded that before psycho-educational program intervention, more than half of (study and control groups) had severe level of depression. But after psycho-educational program, it was found that drug addict patients (study group) had less depression than control group who don't receive it.

\section{Recommendations}

Based on the current study findings, the following recommendations are suggested:

1. Proper follow up and management of psychological problems among drug addict patients to prevent relapse.

2. Psycho-educational program should be included in the treatment strategies among drug addict patients and their families.

\section{Reference}

1. Ahmadi, J., Arumalla, V., \& Rayan, A., (2016): Positive effect of low dose of buprenorphine in the treatment of severe hashish withdrawal craving: An original arcade. J Addict Depend, Vol. (2), No (2), Pp. 1-13.

2. American Medical Association (2015): Substance abuse and mental health, anxiety, depression and drug addiction, help guide.org; Pp. 47-57.

3. Ansari-Moghaddam, A., Rakhshani, F., Shahraki-Sanavi, F., Mohammadi, M., MiriBonjar, M., \& Bakhshani, N., (2016): Prevalence and patterns of tobacco, alcohol, and drug use among Iranian adolescents: A metaanalysis of studies, Children and Youth Services Review; Vol. (12), No (6), Pp. 68-79.

4. Anagnostou, E., Boyle, M., Brian, J., Burack, J., Couture, M., \& Fombonne, E., (2018): drug addiction, cannabis-it matters how young you start, the Canadian Journal of Psychiatry; Vol. (75), No(2), Pp.721-722.

5. Arseneault, C., Alain, M., Plourde, C., Ferland, F. Blanchette-Martin, N \& Rousseau, M., (2016): Impact evaluation of an addiction intervention program in a quebec prison, Substance abuse, research and treatment; Pp. 2264.

6. Austic, A., (2015): Peak ages of risk for starting nonmedical use of prescription stimulants, Drug and alcohol dependence; Vol. (15) No (2), Pp. 224-229.

7. Bartha, C., Parker, C., Thomson, C., \& Kitchen, K., (2014): Depression An information 
guide, Centre for Addiction and Mental Health; Pp.24-29.

8. Beck, A., (1961): Inventory for measuring depression, Arch Gen psychiatry; Pp.61-71.

9. Bornovalova, M., Gratz, K., Daughters, S., Hunt, E., \& Lejuez, W., (2012): Initial RCT of a distress tolerance treatment for individuals with substance use disorders, Drug and alcohol dependence; Vol. (122) No (2), Pp.70-76.

10. Calsyn, D. Cousins,S. Hatch-Maillette, M. Forcehimes, A. Mandler, R. Doyle, S. \& Woody, G (2010): Sex under the influence of drugs or alcohol, Common for men in substance abuse treatment and associated with high-risk sexual behavior, The American journal on addictions; Pp.119-127.

11. Clark, E. Samnaliev, M. McGovern, P (2010): Impact of substance disorders on medical expenditures for medicaid beneficiaries with behavioral health disorders, Psychiatric Services; Vol. (60) No (1), Pp.35-42.

12. Comer, B. and Ronald, J (2014): Substancerelated disorders. Depression symptoms, Abnormal Psychology, New York, NY: Worth; Pp.278-298.

13. Conner, K. Pinquart, M. \& Gamble, A (2009): Meta-analysis of depression and substance use among individuals with alcohol use disorders, Journal of substance abuse treatment; Vol. (37) No (2), Pp.127-137.

14. David, B (2011): Substance abuse, what is the relationship between depression and substance abuse? Journal of Substance Abuse Treatment; Pp. 119-125.

15. El-Sawy, H. Abdel Hay, M. \& Badawy, A (2010): Gender differences in risks and pattern of drug abuse in Egypt, Egypt J Neural Psychiatry Nero Surge; Pp. 413-418.

16. Fortier,E. Alavi, M. Bruneau, J. Micallef, M. Perram, J. Sockalingam, S. \& Bath, N (2017): Depression, anxiety, and stress among patients with chronic hepatitis $\mathrm{C}$ virus infection and a history of injecting drug use in New South Wales, Australia. Journal of Addiction Medicine; Pp.1018.

17. Giardiellom P (2018): Youth identities, media discourse in the formation of youth identity, Language, Identity and Symbolic Culture, Pp. 8599.

18. Hunter, S. Watkins, K. Hepner, K. Paddock, S. Ewing, B. Osilla, K. \& Perry, S (2012): Treating depression and substance use: a randomized controlled trial, Journal of Substance Abuse Treatment; Vol. (43) No (2), Pp.137-151.

19. Jabeen, S. Raja, S. Saeed, S. Zafar, M. Ghani, A. Mahmood, A and Raja, G (2017): Factors influencing vulnerability towards heroin addiction in a Pakistani Cohort, Pakistan, J. Zool; Pp. 9599.

20. Johnson, J., \& Zlotnick, C., (2008): A pilot study of group interpersonal psychotherapy for depression in substance-abusing female prisoners, Journal of Substance Abuse Treatment; Vol. (34) No (4), Pp.371-377.

21. Martinez-Vispo, C., Martinez, U., LopezDuran, A., Del Rio, E., \& Becona, E., (2018): Effects of behavioral activation on substance use and depression: a systematic review, Substance abuse treatment, prevention, and policy; Pp.3640.

22. Marwan, M., (2018): Egypt Drug Addiction, Egypt fights a losing battle against drugs, Egypt Medical Journal; Vol. (2) No (1), Pp.1-7.

23. Mather, C. Rehm, J., \& Popova, S., (2015): National Drug IntelligenceCenter, The economic impact of illicit drug use on American society, Global burden of disease and injury and economic cost attributable to alcohol use and drug use; Pp.223-233.

24. Maye, R., \& Serrano, N., (2012): Psychiatric Mental Health Nursing, drug addiction, depression and Nursing intervention, second edition; p.542.

25. McHugh, K., Votaw, V., Bogunovic, O., Karakula, L., Griffin, L., \& Weiss, D., (2017): Anxiety sensitivity and nonmedical benzodiazepine use among adults with opioid use disorder, Addictive Behaviors; Pp. 283-288.

26. Meray, M., Ahmed, F., \& Rania, A., (2016): Study of Drug Abuse among University Students in Sohag, Egypt, Journal of Forensic, Toxicology and Medicolegal Analysis; Vol. (2) No (1), Pp. 19-23.

27. Mohamed, N., El Hamrawy, L., Shalaby, A., El Bahy, M., \& Allah, M., (2015): An epidemiological study of tramadol $\mathrm{HCl}$ dependence in an outpatient addiction clinic at Heliopolis Psychiatric Hospital, Menoufia Medical Journal; Pp. 59-66.

28. Mohamed, R., Hammad, A., El Hamrawy, G., Rajab, Z., El Bahy, S., \& Soltan, R., (2014): Dual diagnosis and psychosocial correlates in substance abuse in Menoufia, Egypt, Menoufia Medical Journal; Vol. (26) No(2), Pp.1-14.

29. Polger, V., \& Michael, S., (2003): Beck Depression Inventory, gale encyclopedia of mental disorders, encyclopedia, and com. 
30. Rohde, P., Turner, C., Waldron, H., Brody, L., \& Jorgensen, J., (2018): Depression change profiles in adolescents treated for comorbid depression/substance abuse and profile membership predictors, Journal of Clinical Child \& Adolescent Psychology; Pp.595-607.

31.Sancho, M., De Gracia, M., Rodríguez, R., Mallorqui-Bague, N., Sanchez-Gonzalez, J., Trujols, J., \& Menchon, M., (2018): Mindfulness-based interventions for the treatment of substance and behavioral addictions: a systematic review, Frontiers in psychiatry, Vol. (44) No (9), Pp.78-88.

32. Thilo. B., (2014): Substance abuse, Psycho education in Substance abuse Treatment, J Psychiatric Res; 40(5): 394-403.

33. Volkow, N., (2014): Drug addiction, brains and behavior, The Science of Addiction; Vol. (44) No (1), Pp.570-580.

34. Womack, S., Shaw, D., Weaver, C., \& Forbes, E., (2016): Bidirectional associations between cannabis use and depressive symptoms from adolescence through early adulthood among atrisk young men. Journal of Studies on Alcohol and Drugs; Vol. (77) No (2), Pp. 287-297.

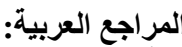

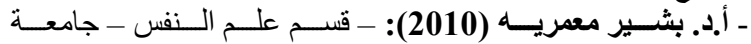

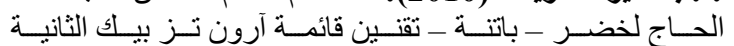

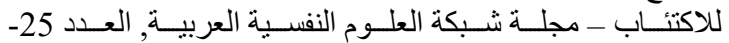

26ثناء \& ربيع 2010م ،صفحة 17-17. 